\title{
Exenciones de almojarifazgo y de otros derechos sobre el tráfico comercial en el reino de Murcia (siglos XIII-XV)
}

\author{
José Damián González Arce
}

Universidad de Murcia

Resumen

La práctica totalidad de las localidades del reino de Murcia recibieron a lo largo de la baja Edad Media generosos privilegios reales que suprimían o rebajaban las cargas fiscales aduaneras, sobre todo el almojarifazgo, el portazgo y el diezmo. Tales mercedes les fueron concedidas por ser un territorio fronterizo y escaso en recursos, que siempre se mantuvo poco poblado, de modo que los monarcas, mediante dichas ventajas, pretendieron atraer a un mayor número de pobladores y potenciar el desarrollo económico, gracias al intercambio mercantil con las regiones vecinas o por vía marítima.

Palabras clave

Fiscalidad, impuestos, aduanas, comercio

Códigos JEL: H3, N4, E62, F13

\author{
EXEMPTIONS OF THE ALMOJARIFAZGO AND OTHER \\ COMMERCIAL TRAFFIC RIGHTS IN THE KINGDOM OF MURCIA \\ (XIII-XV CENTURIES)
}

Abstract

Almost all the towns of the kingdom of Murcia received generous royal privileges throughout the late Middle Ages that suppressed or lowered the customs tax burden, especially the almojarifazgo, the toll and the tithe. Such grants were granted to them as a borders territorys and scarce in resources, which always remained sparsely populated, so that the monarchs, through these advantages, sought to attract a greater number of settlers and enhance economic development through trade with the neighboring regions or by the sea. This paper reviews such tax exemptions and how those who obtained them fought for your accomplishment.

\section{Keywords}

Taxation, taxes, customs, trade

JEL codes: H3, N4, E62, F13

Fecha de recepción del original: 10 de julio de 2018; versión definitiva: 3 de abril de 2019.

José Damián González Arce , Profesor Titular del Departamento de Economía Aplicada, Área de Historia e Instituciones Económicas Facultad de economía y Empresa, Universidad de Murcia. Campus de Espinardo, 30100 Murcia Tel.: + 34 9868888752; E-mail: josedam@um.es.

ORCID ID: 0000-0002-3296-0554 


\title{
Exenciones de almojarifazgo y de otros derechos sobre el tráfico comercial en el reino de Murcia (siglos XIII-XV) ${ }^{1}$
}

\author{
José Damián González Arce \\ Universidad de Murcia
}

1. Introducción

El presente trabajo tiene por objetivo analizar la política regia de exenciones del almojarifazgo aduanero en las tierras murcianas en la baja Edad Media, que, generalmente, incluían, además, otros derechos de paso; como el portazgo, que sabemos era similar, al demandarse también por la entrada y salida de mercancías de las poblaciones; el diezmo aduanero, en este caso sobre las importaciones y exportaciones fuera del reino; $y$, otros marginales, como rodas, castillerías, peajes...

La concesión de estas franquezas nos desvela cuáles eran los intereses económicos y políticos de los monarcas en cada período y coyuntura ${ }^{2}$. Además, como nos recuerda Epstein (2009: 195), estas gracias fiscales fueron una herramienta de centralización política mediante la que los estados afirmaron su soberanía sobre los impuestos y el comercio.

El portazgo, fue na renta de origen romano demandada en la Castilla medieval por reyes, señores y concejos sobre el tránsito comercial en sus respectivas jurisdicciones. Sobre sus variantes y naturaleza me he ocupado en otras partes. Se exigía según complejos aranceles en los que se gravaba cada mercancía en una cantidad fija en especie o dinero, en función de su peso, volumen o precio, y, a veces, ad valorem. Por su parte, el diezmo aduanero fue un gravamen ad valorem de en torno a ese diez por ciento, cobrado en las adunas exteriores del reino, aparecido en tiempos de Alfonso X.

Cuando Alfonso VI conquistó Toledo incorporó al erario real, entre otras, las tasas sobre la circulación comercial exis-

\footnotetext{
${ }^{1}$ Este artículo ha sido realizado en el marco del proyecto HAR2013-45788-C4-1-P“E Negocio de la Fiscalidad": arrendamientos, gestión fiscal y deuda pública (fines siglo XV-1556), integrado en la red Arca Comunis.

2 Para un análisis general sobre las políticas regias en materia comercial y de reducción de las cargas aduaneras en toda Castilla, ver Porras Arboledas (1992: 161-211).
}

tentes en la ciudad de tiempos musulmanes, las que en un primer momento integró, junto con las restantes de dicha época, dentro del portazgo, de modo que éste se convirtió en un conjunto de rentas diversas más que en un único impuesto sobre el comercio. Con el tiempo, dicho agrupamiento, con una cantidad considerable de arbitrios de pasado islámico, más de 20, mucho más numerosos e importantes por su volumen de recaudación que el propio portazgo y otros de origen castellano en él comprendidos, hubo de cambiar de nombre y buscar una denominación más acorde con esta realidad; sobre todo cuando se sucedieron las exenciones del propio portazgo, para evitar dar a entender así que lo franqueado eran todas las rentas integradas en su seno y no sólo el derecho comercial. De este modo, surgió un nuevo término, el almojarifazgo, un vocablo castellanizado de raíz árabe, derivado de al-musrif, o almojarife, funcionario que en el mundo musulmán se encargaba de recaudar los impuestos y, entre ellos, uno de los más relevantes, el gravamen sobre el comercio. De manera que el compendio de arbitrios que antes era conocido como portazgo pasó a denominarse almojarifazgo, tanto en Toledo, como en las ciudades del sur conquistadas al Islam, luego aforadas según el derecho local toledano. En él, el tributo sobre la circulación de mercancías, de igual nombre, vino a sustituir al diezmo aduanero, sobre todo porque, fruto de las mercedes reales para favorecer la repoblación, esta gabela ya no era en muchas ocasiones del $10 \%$, sino inferior, por lo que no podía mantener dicho apelativo. Mientras que, prácticamente, todos los portazgos acabaron por ser cedidos a los concejos, para engrosar los propios municipales, a veces también a grandes señores o a la iglesia, o, simplemente desaparecieron. De manera que pocos de ellos fueron conservados por la hacienda regia, debido a la pérdida de valor que supusieron las sucesivas redenciones y la bajada en la recaudación efectiva de una renta fija, afectada por la inflación de precios y la devaluación monetaria. Asimismo, también con el paso del tiempo, en muchos de los almojarifazgos reales locales perdieron importancia la mayor parte de los derechos no aduaneros que, como el portazgo, fueron otorgados a los consistorios, nobleza y clero, para restar 
en ellos, a veces casi de forma exclusiva, la tarifa arancelaria (González Arce, 1992b: 239-283; 2005: 39-43; 2012: 670; 2013: 100-105; 2014a: 85-87; 2014b: 123-127; 2014c: 243-249).

\section{Las primeras exenciones del siglo XIII}

El fuero de Murcia, recibido de Sevilla en 1266, implicó la aplicaron en la primera de los privilegios puntuales dados a la población andaluza hasta esa fecha en materia de franquezas fiscales. Además, fue eximido el portazgo para todos, vecinos y forasteros, durante la feria local. Luego vino una exoneración temporal para que los avecindados no lo pagasen en toda Castilla, salvo en Toledo y Sevilla, por un período de 6 años. Mientras que a los extranjeros les fue rebajado el gravamen en Murcia a solo el 6\%, durante otros 4 ejercicios. En 1282 Alfonso $\mathrm{X}$ premió a los murcianos, por su apoyo en el enfrentamiento sucesorio contra su hijo, con exención total para la entrada y salida de sus mercancías, incluidos diezmo y almojarifazgo, lo que implicaba que las podían llevar por toda Castilla francamente. Esta concesión especial, que se reiteró en 1283, duró lo que el reinado del propio rey, pues con su llegada al trono Sancho IV reintegró algunas rentas a la hacienda regia, y no confirmó la antedicha libertad. Aunque sí lo hizo su hijo Fernando IV, en 1305 (González Arce, 1992a: 78-79).

La política fiscal seguida por Alfonso X, y sus sucesores, tuvo en el reino de Murcia una de sus expresiones más acabadas. Gracias a la documentación conservada resulta posible estudiar la supresión de las viejas exacciones fiscales, la implantación de las nuevas y su posterior modificación a tenor de las circunstancias. El portazgo y el diezmo aduanero sufrieron de este modo un proceso de evolución y adaptación, al que no escapó el almojarifazgo, marcado por las amplias exenciones concedidas, cuando se comprobó la imposibilidad de mantener los altos tipos impositivos, tras el parcial fracaso repoblador.

Si la exigencia del portazgo pudo favorecer la aparición de una producción local, al gravar las importaciones, en una regionalización de la economía, su desaparición supuso aún mayores ventajas. De un lado dejaba expedito el camino para futuras exportaciones, facilitaba la afluencia de materias primas y, lo más importante, limitaba la competitividad de la producción foránea a la villa, al tratarse de una exención selectiva que sólo beneficiaba a sus habitantes; lo que beneficiaba a la economía regional, tanto al consumo interno como a la exportación. Junto a ello se potenció el desarrollo de un sector mercantil autóctono, agraciado por dichas redenciones que propiciaban que se retuviera el valor añadido de los intercambios dentro del lugar, en la persona de los comerciantes vecinos y moradores. Lo mismo puede decirse tanto del almojarifazgo como del diezmo.

En el Imperio Musulmán, el segundo califa ortodoxo instauró un impuesto sobre el comercio exterior de cada país o localidad inspirado en el Imperio Romano. El canon era del $10 \%$ para los mercaderes no originarios de territorios tributarios al Islam, del 5 para los originarios y del 2,5 para los musulmanes (Abboud-Haggar, 1997: 192; 2008: 498). Curiosamente, siglos más tarde en Sevilla se repitieron estas tarifas. Así, según el padrón de 1491 la tasa general continuaba fijada en el 10\%, sobre todo para las importaciones desde tierras musulmanas como Berbería o desde lugares no amigos; pero a los productos castellanos o procedentes de países aliados o con acuerdos mercantiles signados con Castilla, la gran mayoría, les fue rebajada al 5\%; por último, el género sacado por el mismo importe del introducido, o mercancía de retorno, estaba exento, mientras que las restantes exportaciones fueron gravadas con el 2,5\% (Ladero Quesada, 1969: 109-115). Ese diezmo sobre el comercio exterior, similar por tanto al exigido sobre las cosechas agrícolas y ganados, sería el que encontraron los reyes cristianos cuando conquistaron las diferentes taifas andalusíes, a partir de la caída del reino de Toledo (1085); y el que los emires musulmanes cobraban sobre el intercambio mercantil con otros emiratos, que luego pasó a ser recaudado por la hacienda real castellana; que mantuvo el statu quo previo y los aranceles por el tránsito de bienes entre los nuevos reinos incorporados, y entre éstos y el resto de la Corona. Dicha exacción acabó por ser denominada almojarifazgo, como sabemos.

En 1267 Alfonso X franqueó parcialmente el pago del diezmo aduanero a los vecinos murcianos, que quedó reducido al $2 \%$ de aquellas mercancías que se sacasen o metiesen de los restantes reinos castellanos; que además estaban libres de portazgo y almojarifazgo, salvo en Toledo y Sevilla, y además tenían el retorno exento por el mismo valor de lo importado o lo exportado. El rey, como en otros casos, estaba dispuesto a que el beneficio de estos privilegios solamente recayera en Murcia y no perjudicase a su erario, a la vez que se retenía la plusvalía en la ciudad. De modo que, si los residentes no vendían las mercancías en ella y las llevaban a otros lugares del resto del reino o a Castilla, debían pagar completo el diezmo, descontado ese $2 \%$. Más claramente se aprecia esta voluntad de potenciar económicamente a la capital y a sus moradores en la parte en la que este privilegio establece que por la exportación de sus productos fuera del reino de Murcia, y por ellos mismos, sólo se debía pagar el 1\% en concepto de diezmo o almojarifazgo. Los comerciantes extranjeros también se vieron favorecidos por este paquete de mercedes, al quedar rebajados los derechos de aquello que introdujesen del 6 al $5 \%$, con franqueza total para la mercancía de retorno; tanto en concepto de diezmo como de almojarifazgo. Si lo metido era sacado fuera del reino de Murcia a Castilla, se debía pagar el diezmo completo, excepto el 5\% ya abonado; así como portazgo y otros tributos. Si por el contrario lo que querían era llevar mercancía murciana fuera del reino de Murcia, sin previamente traer otra sino comprada con dinero, el canon que se les exigiría era aún mucho menor, de sólo el 2,5\%; sin tener que dar nada más en concepto de diezmo o almojarifazgo.

En 1257, el citado monarca fijó en el 8\% el gravamen del almojarifazgo de Alicante. Diez años más tarde, en 1267, lo redujo al $6 \%$ para los comerciantes extranjeros que fuesen a Murcia, con el claro propósito de potenciar su abastecimiento. En 1271 eximió a los vecinos del pago de diezmo o almojarifazgo 
de aquellas mercancías que trajeren, compraren o vendieren en la villa. También les rebajó los derechos pagaderos en Murcia, que quedaron en solo el $1 \%$-del $5 \%$ que se estipuló para los mercaderes forasteros-, incluida, además, exención en la mercancía de retorno, tanto de almojarifazgo como de diezmo. Si por el contrario los vecinos alicantinos lo que querían era comprar con dinero en Murcia, la exacción se situó apenas en el 0,5\%. Y, si como ocurriera con Murcia, los artículos introducidos por los alicantinos en la capital eran luego llevados al resto de Castilla, por ellos debían entregar el diezmo completo, excepto el $1 \%$ ya satisfecho. En el caso de los mercaderes foráneos, éstos igualmente obtuvieron ventajas en Alicante, al ver recortado el tipo al 4\%, frente al anterior $8 \%$, en razón de diezmo o almojarifazgo; a la vez que se les concedió exención por la mercancía de retorno. Pero si los productos no eran finalmente vendidos en Alicante, y sin embargo eran llevados a Murcia, allí debía pagarse lo que los mercaderes forasteros, el 5\%, aunque asimismo con retorno exento. El diezmo se tenía que abonar completo si en lugar de a Murcia las mercancías sacadas de Alicante se transportaban fuera del reino de Murcia, excepto lo ya entregado en la capital; suponemos que de lo que se debía pagar en Murcia también se descontaría lo ya dado en Alicante. Si lo que pretendían los comerciantes forasteros era comprar en ésta con dinero, estaban obligados a allegar al almojarifazgo local el $2 \%$-mientras que en Murcia se satisfacía el 2,5\%-. Las mercancías llevadas a Alicante, procedentes de Berbería u otros lugares, por mar o tierra, debían tributar, como en Murcia, por su venta, puesta a la venta o exhibición; aunque no si no se hacía algo de esto, pues podían ser sacadas libremente por el mismo sitio por donde se introdujeron, mientras tanto permanecerían en depósito en la aduana de la ciudad, como en Murcia. Frente a los comerciantes foráneos, los murcianos solo debían pagar al almojarifazgo de Alicante los mismos derechos que en Murcia.

Cartagena, por motivos de decadencia económica e inseguridad fronteriza, debido al riesgo que representaba la piratería del norte de África, estaba totalmente franqueada en las mercancías que se llevasen a vender al reino de Murcia o en el resto de Castilla; al igual que los vecinos y forasteros estaban exentos de todo derecho por la venta de sus productos en la villa, mientras que si los llevaban de ésta a Murcia debían entregar solo el $2 \%-y$ no el $2,5 \%$ - A comienzos del siglo XVI el concejo de la ciudad realizó una probanza para demostrar estas libertades. Según ella, los mercaderes cristianos llegados a la plaza estaban quitos de gravámenes por todo lo que allí vendiesen y comprasen; aunque si llevaban sus artículos desde allí hasta Murcia debían dar el antedicho 2\%. Esta probanza estuvo motivada en que los almojarifes murcianos habían comenzado unos 15 años atrás a exigir una tarifa superior a ésta. Así, en la aduana de la capital cobraban el 5\% a los mercaderes forasteros por los paños y otras mercancías que importaban con destino a Castilla ${ }^{3}$.

\footnotetext{
3 Archivo General de Simancas (AGS), Escribanía Mayor de Rentas, 101-1. González Arce, (1995: 94-116; 1992a: 78-79, 91-97; 2002a: 77-90; 2002b: 61-97; 2004: 141-164); Ladero Quesada (1993: 143-146).
}

\section{Los recortes del siglo XIV}

Estas situaciones tan excepcionalmente ventajosas no podían mantenerse en el tiempo, pues de hecho prácticamente habían suprimido los aranceles comerciales del reino de Murcia. De manera que cuando se comenzó a recomponer la situación política, ya durante la regencia de Alfonso XI, a consolidar el territorio repoblado y a recuperar la actividad económica, tras la muerte prematura de Fernando IV y el desgobierno a que dio lugar, el margen de privilegio de las localidades beneficiadas por las citadas ventajas comenzó a ser rebajado. $Y$ lo hizo en proporción a su nivel de desarrollo, de manera que las más importantes, como Murcia, sufrieron los mayores recortes; mientras que otras poblaciones más pequeñas o de importancia secundaria retuvieron mayores márgenes de exención, caso de Lorca o algunas poblaciones del señorío de Villena, que consiguieron que sus mercedes fuesen respetadas en el largo plazo. La explicación a esta situación es bien sencilla, la monarquía no podía consentir que las localidades del sureste peninsular dejasen de tributar en el ámbito mercantil al erario real, en un período de grandes necesidades hacendísticas por las guerras contra el Islam, vecino a esos territorios; por el contrario, no importaba tanto que las pequeñas villas y las poblaciones fronterizas gozasen de menor presión fiscal. Al tiempo, el crecimiento económico de dichas ciudades ya era lo suficientemente grande como para que un aumento de las exacciones no se tradujese en su despoblación o en un retroceso significativo de su actividad comercial; cosa que sí podía ocurrir con las inseguras poblaciones fronterizas a las que se mantuvo más privilegiadas. Y, por último, de ninguna manera se podían mantener tan amplios márgenes de franqueza en núcleos urbanos de primer orden en los que habría bastado que los comerciantes extranjeros o foráneos se instalasen de forma habitual para escapar casi por completo al pago de impuestos de tránsito; cosa que sí se permitió en las despobladas y precarias plazas de la frontera.

En 1313 el concejo de Murcia se quejó a los regentes porque los almojarifes no respetaban la franqueza dada por Alfonso $X$, que fue confirmada por éstos. Sin embargo, los arrendatarios siguieron sin observar las libertades, para lo que argumentaron que fueron concedidas a causa de las luchas civiles. A lo que el consistorio replicó que la merced se debió a que el reino de Murcia era tierra de frontera, muy seca y en la que casi no se obtenían cultivos, salvo en los terrenos de regadío, que eran pocos; de manera que las gentes apenas podían sobrevivir, sobre todo durante las contiendas, y la mayor parte de los productos que consumían eran transportados desde fuera. Así que alegó poder importar en tiempo de guerra y libres de gravámenes caballos, armas, ganados, carne (fresca y salada), pescado (fresco y salado), cebada y otros mantenimientos. No obstante, algunos artículos básicos no estaban libres de almojarifazgo, caso del queso, aceite y vino, que no eran tenidos por viandas, así que la población debía subsistir a base de higos y legumbres, pues no se hallaba pan; hasta que 
el municipio consiguió de Alfonso XI que todos los comestibles fuesen eximidos durante los enfrentamientos bélicos. Los recaudadores trataron igualmente de soslayar el privilegio de franqueza de la feria de Murcia. Tras un primer intento en la década de 1330 de suspender temporalmente por dos años todas las franquezas a Murcia, Lorca, Mula y Chinchilla, en 1342 el citado monarca arguyó nuevos aprietos hacendísticos para hacerlo otra vez, ahora por tres años. Mientras que en la carta de recudimiento del almojarifazgo del bienio 1373-74 se dice que los vecinos de Murcia gozaban de la misma exención que los de Sevilla y Córdoba, aunque los enfrentamientos entre el municipio y los arrendatarios hicieron que Enrique II tuviese que clarificar las exenciones. Los murcianos de intramuros, como los sevillanos y cordobeses, estaban libres de almojarifazgo por sus cosechas y ganados, así como de derechos por la compara de caballos y armas; sin embargo, para que sus franquezas no fuesen mayores que las de los andaluces, no les consintió estar redimidos de abonarlo por todos los productos que importasen o exportasen, merced que habían disfrutado en reinados anteriores.

Con Juan I se sucedieron recortes y ampliaciones en los márgenes de franquicia en función de los vaivenes políticos. Así, por ejemplo, hasta 1385 las franquezas eran las esenciales, esto es, para los vecinos de intramuros y sólo por sus cosechas y ganados. Sin embargo, tras la derrota de Aljubarrota de ese año, el rey confirmó los privilegios máximos de exoneración de almojarifazgo, de todo lo importado y exportado. Más adelante, el arrendamiento de 1387-88 volvió a incluir solamente la redención mínima. Por el contrario, en el reinado de su hijo Enrique III fueron los avatares de la política regional los que marcaron la presión fiscal. En 1393 Murcia envió un mensajero a Toledo, Córdoba y Sevilla, ciudades con las que compartía usos forales y exención de almojarifazgo, para que le informasen sobre los términos de la misma. Quería saber si se aplicaba a la grana y madera de los términos municipales, así como a los paños fabricados con lana local, o si los hidalgos gozaban de libertad para la importación de esa materia prima y de tintes con destino a la industria textil. La capital hispalense respondió que dese tiempos de la conquista sus vecinos estaban enajenados de almojarifazgo y otros derechos, como portazgo y diezmo, de cuantas cosas comprasen o vendiesen, llevasen o trajesen, tanto por mar como por tierra. Sin embargo, tras Sancho IV, los reyes posteriores quebrantaron esas libertades, de forma que desde Enrique II solamente afectaban a las cosechas de los vecinos - cereal, vino, ganados, aceite, cueros, miel, cera y lana- y a los paños, tanto si los vendían en tierra como si los exportaban por mar ${ }^{4}$.

Yecla fue redimida desde que obtuvo el fuero de Lorca, en tiempos de don Juan Manuel, del pago de diezmo, portazgo y almojarifazgo por los bienes destinados a sus vecinos. Privilegios defendidos por los yeclanos contra los señores de Villena, a los que pertenecía el lugar, cuando éstos intentaron restrin-

\footnotetext{
${ }^{4}$ En este período no todo fueron restricciones, a las confirmaciones de las exencio nes concedidas durante el siglo anterior, se unió la franqueza para la importación de lanas y tintes con las que potenciar la industria textil murciana, dada en 1314 y ampliada en 1328; privilegios confirmados por Pedro I en 1352, pero no siempre respetados por los almojarifes, como ocurrió en 1384, 1397 y 1413 (González Arce, 1999: 95-101; 2012: 672-683); Collantes de Terán (2013: 294-296).
}

girlos, para lo que recurrieron en su socorro a la monarquía. Como ocurrió en 1484, cuando los Reyes Católicos confirmaron las franquezas de la villa y las hicieron extensivas a los puertos de Murcia, Lorca y restantes de Castilla (López Serrano, 1997: 260-261; Ortuño Molina, 1997: 189-190).

4. El siglo $X V$, respeto de ciertas franquezas y aumento de la presión fiscal

Los intentos de las poblaciones murcianas por conseguir la observancia de sus privilegios de exención fiscal, solamente cosecharon un éxito más claro en aquéllas menos pobladas y más expuestas al peligro fronterizo, pues, de lo contrario, se habrían despoblado o reducido muy significativamente el número de sus habitantes. Mientras que, como hemos visto, las restantes solamente pudieron conservar algunas ventajas reducidas a su mínima expresión. A este aumento de la presión fiscal por vía del recorte de las mercedes, se unió la implantación en el reino del diezmo aduanero a finales del siglo XIV.

Precisamente, su carácter fronterizo, que mantuvo durante casi tres siglos, hizo de Lorca una de las localidades más beneficiadas por las mercedes. Privilegios que siempre estuvo dispuesta a hacer respetar. En 1413 los alcaldes de Murcia fallaron en un pleito interpuesto por el concejo lorquino contra el almojarife Juan Sánchez de Torres, arrendatario del impuesto en el obispado de Cartagena y de la aduana mayor de la capital, residente en ésta, en favor del primero, que había mostrado, a través de sus privilegios, que sus vecinos eran ajenos al pago de almojarifazgo, tanto en Murcia como en las otras poblaciones de la Corona. Máxime cuando los moradores de Villena, que habían obtenido las franquezas lorquinas, gozaban de la citada exención. Un caso similar se reprodujo en 1433 en Chichilla, otra localidad del señorío de Villena, en la que su corregidor pronunció una sentencia judicial a favor de Lorca, a tenor de los privilegios que ésta tenía de Murcia para no dar derechos de paso - portazgo, diezmo y otros-, confirmados por los regentes de Juan II, en 1407. En 1421 el concejo lorquino protestó ante el de Murcia porque, a pesar de sus privilegios, cuya copia mostraban a los almojarifes cuando iban a la capital, éstos no querían respetar sus gracias; los regidores murcianos dieron encargo a los alcaldes presentes y futuros para que no tolerasen dichos abusos. Lo que no sirvió de gran cosa, pues de nuevo en 1427 el consistorio del Guadalentín hubo de escribir en varias ocasiones al del Segura quejándose de nuevos agravios de los exactores, sin que las promesas de intervención en su favor del ayuntamiento de la capital tuviesen mucho efecto. De manera que Lorca volvió a solicitar en 1431 otra vez la mediación de Murcia, en esta ocasión recordándole que la participación del ayuntamiento lorquino era decisiva para que los arrendatarios no demandasen el gravaban a los murcianos en dicha ciudad. 
Los lorquinos no sólo estaban exonerados de satisfacer el almojarifazgo aduanero por el tráfico comercial, sino también las otras rentas sobre diversas actividades económicas comprendidas en su seno, que pervivían desde la conquista. Según se desprende de otro litigio por ellos ganado en 1435 contra Rodrigo Alonso Fructuoso, recaudador del almojarifazgo de Hellín, localidad asimismo del señorío de Villena donde todavía se exigían este tipo de derechos. Quien actuaba en nombre del arrendatario mayor de la exacción, que pertenecía al marqués, Yehuda Abenpica, y del menor, Ferrán Ruiz de Fresneda, que, como Alonso, era hellinero. La demanda la había interpuesto un rabadán de Librilla que había llevado a pacer varias vacas de vecinos de Lorca a la mencionada población, y al que el almojarife había exigido tasas de herbaje y montazgo; que, según la sentencia del alcaide merino de Hellín, los lorquinos no tenían que pagar, gracias a su exención ${ }^{5}$.

A pesar de que en 1491 la ciudad elevó ante los Reyes Católicos una queja por la inobservancia de su franqueza de derechos de tránsito, y de que éstos ordenaron una investigación sobre el alcance de la misma, hacia 1493 hubo de iniciar un pleito para hacer valer su exención de almojarifazgo en toda Castilla, en el que se solicitó al arrendatario del almojarifazgo y portazgo locales, Agustín Hurtado, que presentase la carta de recudimiento del impuesto; la cual no entregó, porque alegó no se la había proporcionado el recaudador mayor, García Gutiérrez, y, por ello, el concejo solicitó que fuese condenado en rebeldía, y que a partir de entonces no se le abonasen los citados gravámenes. En dicho pleito se contiene igualmente un interrogatorio que el consistorio realizó a los testigos que presentó, residentes de la propia Lorca, de la cercana Vera, de Cehegín, Caravaca y Murcia; entre otras, con preguntas relativas a si sabían que los vecinos y moradores estaban liberados de pagar almojarifazgo y portazgo en toda Castilla, del pan vino, ganados y otras mercancías de su cosecha, labranza y crianza, así como diezmo y medio diezmo de lo morisco; y que dicha franqueza se tenía por uso y costumbre desde mucho tiempo atrás, hasta que fue incumplida por los arrendatarios de ese año. Dichos testigos corroboraron las afirmaciones concejiles y expusieron que los lorquinos eran quitos de dar en toda Castilla cualquier clase de derechos de tránsito por sus productos, según mercedes concedidas por los monarcas precedentes. Uno de ellos, Juan Bernardo de Quirós, citó el caso de Juan de Baena, también vecino de Lorca, al que se le quiso cobrar almojarifazgo en Córdoba, pero que obtuvo un albalá de los Reyes Católicos para no tener que abonarlo, en función de su vecindad; caso similar al del propio testigo, en esta ocasión en Hellín, adonde acudía con sus mercancías. El mencionado Juan de Baena también expuso su experiencia en Córdoba, así como que no daba portazgo en el trayecto a Toledo nada más que en los lugares de señorío, mientras no lo hacía en los de realengo; asimismo añadió que fue a partir del arrendamiento de Hernando de Madrid (hacia 1491), recaudador del almojarifazgo de todo el obispado de Cartagena, cuando los arrendatarios pretendieron cobrarlo de los vecinos de la localidad. Otro testigo alegó no haber entregado portazgo alguno por

5 Archivo Municipal de Murcia (AMM), leg. 4.277, 6-7; 4.292, 78; AMM Acta Capitular (AC) 1420-21, fols. 65v-66v. García Díaz (2007: 96-98, 100-103). una carretada de cera. Un cuarto, que era práctica habitual que en Córdoba no se demandase portazgo ni almojarifazgo a los lorquinos. Mientras que otro adujo haber satisfecho portazgo y almojarifazgo en Chinchilla, adonde llevó a vender unas 17 arrobas de cáñamo, pues no presentó su vecindad, pero en una venta posterior sí la mostró y resultó exonerado. Los restantes testigos se expresaron en términos similares. Al año siguiente, 1494, los Reyes Católicos daban cuenta de cómo el concejo de Lorca les había hecho saber de su franqueza de derechos de tránsito por su pan, vino, higos, ganados y otras cosas de su cosecha; de modo que los monarcas encargaron al corregidor que se informase al respecto con los testigos presentados por las partes interesadas, el concejo y el arrendatario del almojarifazgo local, Garci Gutiérrez de Madrid. El consistorio presentó además sus privilegios y varias sentencias judiciales favorables a sus pretensiones, entre ellas las vistas más arriba. De manera que los soberanos ordenaron respetar los privilegios lorquinos en adelante. Además, ese mismo año, Lorca remitió al concejo de Murcia la carta de confirmación de sus privilegios de exención dada por los monarcas. No obstante, todo ello no impidió que en 1504 los almojarifes volviesen a intentar cobrar el impuesto, y que en 1506 se iniciase un nuevo pleito ${ }^{6}$.

Como Lorca, Cartagena mantuvo durante siglos su carácter fronterizo, en este caso de confín marítimo expuesto a continuos ataques de piratas berberiscos. Motivo por el que sus mercedes fueron igualmente excepcionales. Tanto que sus vecinos estaban liberados de pagar almojarifazgo en toda Castilla; así como los comerciantes cristianos que vendiesen o comprasen mercancías en la localidad, excepto si las llevaban a Murcia, donde debían abonar el $2 \%$ más arriba visto. Del mismo modo, los cartageneros estaban exonerados de entregar al rey el quinto de las cabalgadas, lo que no les fue respetado por Juan Chacón, adelantado del reino de Murcia, cuando fue titular de la ciudad. Sin embargo, hacia 1503, una vez retornada al realengo, los almojarifes de Murcia quebrantaron estas mercedes al cobrar más del citado $2 \%$; mientras que Juan Chacón, diez años atrás, había exigido un nuevo tributo de nuevo cuño, en forma de anclaje de los navíos que atracaban en el puerto. Por todo ello, los soberanos ordenaron intervenir a las autoridades locales. En 1505 la reina Juana dispuso no exigir en adelante esta exacción ${ }^{7}$.

Otras localidades tomaron similares medidas con el objetivo de mantener las ventajas obtenidas siglos atrás. Uno de los casos más destacados es el de Chinchilla, que ya durante el XIII y comienzos del XIV hubo de pelear para que fuese respetado su amplio margen de exención. Desde ese momento consiguió que los sucesivos monarcas confirmasen sus privilegios, hasta llegar a Felipe III, lo que no impidió que en 1617

\footnotetext{
6 Archivo Municipal de Lorca, planero 3, leja 3. AMM. leg. 4.281, 67; AMM AC 149495 fol. 76r-v. CODOM, XIX: 816-817; XX: 232-235, 1.215-1.216; XXIII: 166-168. Hacia 1495 un juez fallaba a favor de un mercader que sacó grano por Mazarrón sin pagar almojarifazgo, tal y como pretendía el recaudador Francisco de Cáceres, pues el cereal exportado desde Lorca o allí importado por dicho puerto no debía abonar este tributo (García Díaz, 2007: 319-325, 331-332, 345-346). En 1602 fue presentado un testimonio por el que constaba que los vecinos de Lorca, Cartagena, Murcia y Úbeda no pagaban almojarifazgo en la aduana de Sevilla (Archivo Municipal de Sevilla, Privilegios, carpeta $\left.180, n^{\circ} 146\right)$

${ }^{7}$ CODOM, XX: 1.111-1.114; XXIII: 27-29.
} 
se iniciase un extenso litigio contra los almojarifes de Murcia que, una vez más, no querían observar sus franquezas, ganado por la ciudad manchega en 1624. También hubieron de velar por el mantenimiento de sus mercedes otras poblaciones del marquesado de Villena, como Almansa, Yecla, Hellín ${ }^{8}$ o la propia Villena. En 1484 los Reyes Católicos encargaron una pesquisa porque Jumilla alegó que su exención de almojarifazgo y otros derechos de paso, tanto de las mercancías que sus vecinos compraban en Castilla como de las que importaban de Aragón, no le era respetada en Yecla, Alcaraz y Almansa9.

Y a la inversa, uno de los territorios donde los vecinos de Murcia encontraron mayores dificultades para hacer valer sus gracias de exoneración fue el señorío de Villena, especialmente en Chinchilla. En 1410 se inició una querella entre ciertos murcianos contra el almojarife chinchillano, porque les exigía derechos de montazgo, renta comprendida en dicha exacción. De nuevo, el año 1431 un vecino expuso ante el concejo que cuando procedía de tierras castellanas con mercancías, y a pesar de que llevaba copia del privilegio de franquicia, fue obligado a pagar almojarifazgo en Chinchilla, de manera que interpuso un pleito contra los almojarifes, fallado en su contra por los alcaldes locales, y luego una apelación ante la justicia real. Como en dicho proceso había gastado en costas 320 mrs., pidió del consistorio murciano que se los reintegrase, pues los había empleado en defender los privilegios capitalinos, a lo que éste accedió. Algo similar ocurrió en 1434 con otro vecino, al que en este caso hicieron pagar en la localidad manchega 200 mrs. de portazgo, que solicitó al ayuntamiento de Murcia, que se los dio a modo de compensación. En 1459, la capital otorgó una carta de procuración para que su representante hiciese valer sus privilegios de exención de almojarifazgo, portazgo, asadura, servicio y montazgo y otros derechos, tanto ante el rey como ante el marqués de Villena, Juan Pacheco, favorito y mayordomo mayor del monarca, en su Marquesado. Además, fue presentado por el regidor murciano Juan Cascales, ante el concejo de Hellín, un poder del consistorio de Murcia y un cuaderno. El primero, fechado ese mismo año, para solicitar del marqués, de su alcalde mayor en el señorío y de los municipios del mismo y del resto de la Corona que respetasen los privilegios de Murcia relativos a la franqueza de derechos de paso. El cuaderno, con fecha del año anterior, 1458, contenía copia de los citados privilegios. El primero, uno de Alfonso X, fechado en 1267 —aparece erróneamente 1272-, en él se exime de almojarifazgo a los ganados traídos desde Castilla, entre otras concesiones. El segundo es el privilegio alfonsino de 1282 que franqueaba a la ciudad de todo tributo de tránsito. El tercero, el de 1269 que fijaba el portazgo a pagar en el puerto de La Mala Mujer. El cuarto, el de 1283 de renovación

\footnotetext{
8 Fernando IV había concedido a los vecinos de Hellín franqueza de portazgo, diezmo y almojarifazgo en todo el reino de Castilla, de lo que llevasen o trajesen, excepto en Sevilla y Toledo, privilegio confirmado por los Reyes Católicos. Ante quienes en 1494 algunos representantes de los mudéjares allí residentes denunciaron que los arrendatarios del almojarifazgo local no se lo respetaban, pues alegaban que dicha ratificación solamente iba dirigida a los moradores cristianos, lo que era causa de emigración de los moros y de la despoblación de la morería local. Por lo que los monarcas dispusieron aplicar también a ellos la exención y la merced (AGS, Registro General del Sello (RGS), 1494-03, 97).

${ }^{9}$ AGS, RGS, 1484-02, 41. González Arce (2002b: 62-78, 85-86, 92-95; 2002a; 2004).
}

de la libertad total de exacciones de paso. Y, el quinto, las confirmaciones de la supresión de derechos de tráfico mercantil dadas por Enrique II en 1370 y 1372 . Además, se añade una carta de procuración enviada por el concejo de Murcia al marqués Alfonso de Aragón, en 1384, con motivo de la exigencia de montazgo en Chinchilla y Hellín, y el acuerdo con éste para la otorgación de exoneraciones a este respecto y la fijación de las tasas de portazgo en La Mala Mujer. Seguida de otra de don Juan Manuel, de 1320, librando a los murcianos de asadura en su señorío. Y de otras dos, de ese mismo año y de Alfonso XI, en las que ordenaba a Alcaraz no cobrar servicio a los ganados llevados a las carnicerías de Murcia. En otras dos misivas, dicho rey mandaba en 1322 a Garcimuñoz y Huete observar la redención de portazgo de los murcianos. Mientras que una más de don Juan Manuel, de esa fecha, disponía lo mismo a todos los concejos, como regente y adelantado del reino de Murcia. La carta octava está firmada de nuevo por Alfonso XI, en 1347, para instar a Chinchilla y al resto de los castillos del reino de Murcia a que respetasen la franquicia de asadura de Murcia. La novena, la rubrica en 1384 de nuevo el marqués Alfonso de Aragón e iba dirigida a sus almojarifes, a los que ordenó devolver el ganado requisado, tras el acuerdo suscrito con dicha ciudad ese año. Sigue luego otro privilegio de Enrique IV (1455) mediante el cual ratifica uno previo de Juan II (1420), que confirmaba las franquezas de Murcia. Finalmente, el consistorio murciano solicitó de Hellín que cumpliese lo contenido en dichos documentos o se atuviese a las consecuencias. A lo que éste respondió que obedecerían los privilegios reales, pero que desconocían haber agraviado en algo a dicha ciudad. Lo que no debió de ser muy efectivo, pues al año siguiente, 1460, dicho municipio hubo de pregonar que aquellos vecinos que fuesen a comerciar a tierras castellanas, de realengo o señoríos, incluidos los eclesiásticos, llevasen copia de los privilegios de la localidad y, si no les fuesen respetados y mostraban de ello testimonio escrito, él correría con las costas y les resarciría de las tasas indebidas que les impusiesen; algo parecido se dispuso en 1476. Años antes, en 1470 se hizo pagar a un vecino de Murcia por 1.100 cabezas de ganado ovino y caprino cuando pasó por las villas de Hellín y Tobarra, tanto almojarifazgo como otros derechos de los que en teoría estaba exento. Aunque poco después, en 1474, Murcia y Hellín llegaron a un acuerdo para observar y respetar mutuamente sus respectivas mercedes, con mención expresa a la franqueza de almojarifazgo, portazgo y diezmo aduanero ${ }^{10}$.

En 1421 era pronunciada sentencia por parte del lugarteniente del alcalde mayor de Toledo, en un proceso interpuesto por parte del almojarife local, el arrendatario Juan Alfonso Havete, contra el judío murciano Mayr Abendaño, que allí había llevado 4 cargas de pan de higos a vender, de las que no quiso abonar almojarifazgo, portazgo ni otros impuestos, salvo alcabala, alegando que estaba exento como el resto de los vecinos de Murcia, para lo que presentó su carta de vecindad,

\footnotetext{
10 AMM, leg. 4.278, 5. AMM, Cartulario Real (CR), 1453-1478, fol. 241r-v. AMM, AC 1410-11, fols. $102 \mathrm{v}-103 r ; 1431-32$, fol. 33r; $1434-35$, fol. 17v; $1460-61$, fol. 47v; 1470 71, fols. 57r-58v; AC 1474-75, fols. 108r-109r; 1476-77, fol. 36r. CODOM I: 43-49, 56, 106, 108-109; VI: 24-25, 29, 46-47, 470-471; VIII: 62-63, 158-161; XVIII: 45-48. González Arce (2002b: 139-141, 261-262)
} 
sellada con un sello de cera amarilla colgante. La cual se reproduce $y$, dentro de ella, se contiene una copia del privilegio de exención de Alfonso $X$ relativo a la franqueza de gravámenes de tránsito; ratificado por Juan II en 1420. De manera que el concejo murciano pedía, en dicha epístola, cuya vigencia era de un año, que no se le exigiese al susodicho diezmo, almojarifazgo, portazgo, rotaba, asadura, castillaje, servicio y montazgo, ni otros. A lo que el exactor alegó que el mercader no debía gozar de la franqueza por ser judío. El juez falló a favor del murciano. En 1475, los alcaldes de Lorca, por solicitud del fiel-arrendatario de su almojarifazgo, Gabriel de Jerez, condenaron a los mudéjares murcianos Abdalah Al-Abcaudo y Yusuf Tamblus a pagar almojarifazgo por 300 libras de arambre labrado que allí llevaron a vender, a pesar de estar exentos; motivo por el que el concejo de Murcia, como representante de sus vecinos, presentó una reclamación ante el lorquino. De manera que, en la sentencia definitiva, los jueces declararon que todos los vecinos de Murcia, también los mudéjares y judíos, estaban libres y por tanto no se les debía cobrar el tributo. En 1480 dicho consistorio elevó una solicitud ante los Reyes Católicos, a los que pidió que los mudéjares de la capital no abonasen almojarifazgo, pues estaban franqueados de hacerlo según los privilegios por ellos ratificados. Para dilucidar el asunto se abrió una pesquisa e interrogatorio, que acabó en un pleito hacia 1484. Mientras que en 1488 se pidió al exactor Juan de Torres, probablemente el arrendatario minorista de la renta, que dejase de demandarla a los musulmanes vecinos mientras que no llegase a un acuerdo con el concejo, y que durante ese tiempo éste le abonaría lo que le correspondiese. Otra investigación fue abierta para averiguar si en el reconocimiento de la exención de los vecinos de Hellín, más arriba visto, se cometió cohecho ${ }^{11}$.

El año 1481 eran los comendadores de la orden de Santiago los que se quejaban de que los murcianos pasasen con sus mercaderías por sus tierras -Aledo, Ricote o Cieza-, sin pagar el almojarifazgo; pues, como hemos visto en el caso de Lorca, las exenciones sobre el tráfico comercial parece que de hecho carecieron de validez en los terrazgos de las órdenes militares. Aunque los citados comendadores, por su parte, sí reivindicaban que fuese respetada la franqueza de los habitantes de estos territorios en la capital. De modo que hacia 1490 el concejo murciano negociaba con el comendador mayor de Santiago el reconocimiento, probablemente mutuo, de sus respectivos privilegios. En 1485 ordenó que se pusiese una tabla (listado) en la aduana de la capital en la que constasen las mercancías de las que estaban libres los vecinos y aquellas otras por las que debían abonar derechos, y otra para los forasteros. Mientras que en 1487 estableció que quienes se avecindasen fuesen favorecidos con la redención del impuesto; aunque por contra, los que se extrañasen dejarían de estarlo. Al año siguiente, 1488, elevó una queja ante los monarcas, aprovechando que en ese momento se encontraban en la ciu-

\footnotetext{
11 AMM, CR 1411-1429, fols. 130-131r; 1453-1478, fol. 231r-v. AMM, AC 1474-75, fol. 139r-v; 1480-81, fols. 23r, 31v-32r, 86v; 1483-84, fols. 15v, 84v; 1488-89, fol. 12v; 1484 85 , fol. $14 \mathrm{v}$. En 1500 al platero Antón Gerín, camino de Murcia a Toledo, le fueron embargados ciertos reales viejos por valor de $24.000 \mathrm{mrs}$., porque los almojarifes alegaban que eran mercancía no declarada, a lo que contestó que no lo eran ni debía manifestarlos por ser murciano (AGS, RGS, 1500-09, 243).
}

dad, pues, si bien el privilegio eximía a todos los vecinos, cristianos, mudéjares y judíos, del pago del arbitrio por las mercancías que comprasen o vendiesen, algunos arrendatarios de esta última religión, por enemistad hacia los musulmanes, no respetaban su franqueza. Lo que no fue tolerado por los reyes. Mientras que en 1492 fueron los mercaderes forasteros, tanto nacionales como extranjeros, los que protestaron ante los soberanos contra el consistorio, porque, si bien al morar de forma habitual en la ciudad contribuían en la sisa de la carne y otras imposiciones concejiles, sin embargo no gozaban de la exención de almojarifazgo que tenían los vecinos, para no abonarlo por lo que importasen o exportasen hacia Castilla, otros lugares o por vía marítima; y, además de ello, el ayuntamiento les exigía pagar las sisas destinadas a su sufragar la Hermandad, cuando solo debían afectar a los vecinos.

Ese mismo año 1492, los Reyes Católicos ordenaron la elaboración de un nuevo cuaderno del almojarifazgo para el reino de Murcia, para lo que mandaron que la capital enviase a sus representantes ante los contadores mayores con copia de sus privilegios de exención. Éstos alegaron que era franca de toda exigencia de almojarifazgo, según los privilegios de Alfonso $\mathrm{X}$, confirmados por los monarcas posteriores. Lo que no sirvió de mucho, pues, según el recudimiento de 1498 solamente se respetarían las libertades asentadas en los libros de lo salvado; lo que motivó que se remitiese a los representantes concejiles ante los monarcas para que así se hiciese. Con la unificación de los arrendamientos del almojarifazgo del reino de Murcia, el de la capital y el demandado en Lorca, en uno solo se comenzó a poner solución a los problemas de inobservancia de las exenciones de ambas localidades entre ellas. De este modo, en 1493 el arrendatario, García Gutiérrez, prometía al concejo murciano que ordenaría a su delegado o hacedor en Lorca que respetasen sus mercedes y no lo demandase de sus vecinos. No obste, dicho hacedor, Lope de Siruela, sí cobraba por la manifestación de los productos murcianos, lo que dio lugar a una nueva investigación ante la justicia de la capital en 1494. En 1498 los exactores trataron de no respetar la franqueza de que gozaban los forasteros que, según los privilegios del siglo XIII, podían exportar mercancías exentas por el mismo importe de lo que introdujesen para vender dentro del reino de Murcia, y les exigían por ellas el 2,5\%, lo mismo que por los artículos comprados con dinero y llevados fuera. Para evitar que los vecinos fuesen engañados y se les demandasen derechos de los que estaban libres, el concejo ordenó en 1503 colocar una copia en pergamino de los privilegios en la puerta de la aduana. Todavía en 1510 el almojarife era acusado de cobrar mayores tasas que las estipuladas en los privilegios de exención. Mientras que en 1550 se desató un pleito ante los contadores mayores de la Hacienda entre Sevilla, en cuyo almojarifazgo, que había sido encabezado por la ciudad, se había integrado a finales del siglo XV el murciano, y sus almojarifes, de un lado, y Hernando de Munuera, vecino de Murcia, y el concejo de ésta, del otro, de nuevo a cuenta de la exención del impuesto, que no le había sido respetada al susodicho cuando exportó desde esta localidad cierta cantidad de seda, pues la parte contraria adujo que era vecino toledano y no murciano. En la carta ejecutoria de la sentencia, favorable Murcia, se reproduce un privilegio de confirmación de los Reyes Católicos (1487) en el que 
ratifican el de exención dado por Alfonso X; si bien los contadores dispusieron que el concejo extremase las exigencias a las personas que fuesen a avecindarse a la localidad ${ }^{12}$.

Los privilegios de exención iniciales concedidos en el siglo XIII y comienzos del XIV hablan de la franqueza de portazgo, a veces del diezmo y de otros derechos, sin citar explícitamente al almojarifazgo, denominación que en ese momento se comenzaba a imponer a la del diezmo aduanero, como sabemos. De modo que los almojarifes se ampararon en esta ambigüedad para intentar exigir periódicamente un impuesto que tradicionalmente se tenía por redimido, como los restantes sobre el tráfico comercial. Es lo que en 1494 ocurrió con Mula, que estaba libre del pago de almojarifazgo en Murcia por los productos de su cosecha y crianza. Franqueza que el arrendatario mayor Fernán Núñez Coronel no respetó, de manera que el concejo inició un pleito en su contra en el que alegó que desconocía cómo debía ser percibida la exacción, que era cosa de sus hacedores y recaudadores, a los que había autorizado para que la cobrasen en su nombre, según las leyes del cuaderno de recaudación, donde debía constar la franqueza. No obstante, él había visto los privilegios de la villa y por ellos no parecía que fuese libre, lo que tampoco constaba en los libros de lo salvado. El fallo reconoció la merced, que había sido ratificada en un privilegio de confirmación de Pedro I, de 1351, que recogía el original de Alfonso X, del año 1266, y otro del año 1325, de Alfonso XI, así como en una sentencia de don Juan Sánchez Manuel, como adelantado del reino de Murcia, dada en 1372 (CODOM, XX: 261-265).

También se produjeron irregularidades de signo inverso, o abusos por parte de los privilegiados con las exenciones.

En 1427 el fiel del almojarifazgo de Murcia, Pedro Martínez de Villarreal, y el escribano mayor de la renta, el notario público Juan Rodríguez de Alcaraz, denunciaron que muchos vecinos interceptaban a los mercaderes antes de que llegasen a la ciudad, a la altura de Jumilla, para comprarles sus mercancías, fraude que fue prohibido bajo multa de $600 \mathrm{mrs}$. Se trataría de un abuso por parte de los murcianos que comprarían más baratos los productos a unos comerciantes que no tenían que pagar el gravamen, al no haber pasado por las aduanas de la capital, mientras que ellos podrían introducirlos francamente, gracias a su exención. Por esas fechas la ciudad se hallaba envuelta nada menos que en siete pleitos contra los arrendatarios del almojarifazgo, relativos a sus privilegios en materia de exenciones. En 1438 se denunció algo parecido, que los mercaderes que llevaban artículos a Murcia, tales como herrajes, lanzas y otros, los vendían antes de llegar, en Chinchilla o Hellín, para ir de vacío a la capital y cargar allí naranjas y otras frutas que luego exportaban; el concejo prohibió sacar estas

\footnotetext{
12 AMM, Pergaminos, 150. AMM, leg. 4.280, 30; 4.287, 13. AMM, AC 1485-86, fol. 25r 1486-87, fol. 73r; 1492-93, fols. 85v-86r, 91v-93v; 1493-94, fols. 26r-v, 80v; 1494-95, fol. 54r-v; 1497-98, fol. 69r-v; 1498-99, fols. 44v-45v, 48v-52r; 1503-04, fol. 88r; 1510-11, fols. 83v, 85r-v. AGS, RGS, 1488-06, 26; 1492-11, 71. En 1498 eran suspendidos por los Reyes Católicos los portazgos que se cobraban en el reino de Murcia en manos de órdenes militares o particulares, el de La Losilla y el de Aledo y Totana, mientras que en el de La Mala Mujer continuaban las diligencias judiciales. En 1505 fue denunciado que los vecinos de Fortuna, población perteneciente a la jurisdicción de la capital, eran tratados como forasteros cuando introducían mercancías en ésta, que debían manifestar en su aduana y allí obtener un albalá para poder llevar otras a su localidad (AMM, AC 1498-99, fol. 33r-v; 1504-05, fol. 122r).
}

mercancías si antes no se introducían otras. El fraude, que perjudicaba a las rentas reales, el almojarifazgo entre ellas, consistía en que no se pagaba este impuesto en Murcia, porque los artículos traídos de Castilla y vendidos en La Mancha entraban libremente en la capital, pues los manchegos, como sabemos, contaban con exenciones de dicha exacción. En 1466 otro cohecho consistía en que los tintoreros comprasen tintes importados, baratos porque estaban libres de almojarifazgo, para exportarlos luego y venderlos más $\operatorname{caros}^{13}$.

En 1457 Enrique IV ordenó redactar un cuaderno con las condiciones de arrendamiento del almojarifazgo del reino de Murcia, en el cual se dispuso que, si bien los vecinos de Murcia y Cartagena estaban exentos, no podían acoger por tales a genoveses y otros extranjeros para que dejasen de abonar la gabela o formar compañías con ellos; de manera que si así ocurriese no se podrían beneficiar de las franquezas. Esta disposición fue repetida en un cuaderno posterior, dado por los Reyes Católicos, en 1479 - Nueva Recopilación, IX-XXV-VI-, lo cual no obstó para que en 1507 se cometiese semejante colusión. Tal y como denunciaron los almojarifes al año siguiente que había ocurrido en Murcia, Lorca y Cartagena, donde los vecinos realizaban compañías con forasteros, o los foráneos eran aceptados como vecinos; lo que llevó a Juana I a recordarles la citada normativa. Esto no sirvió de mucho, pues en 1509 los arrendatarios del almojarifazgo de Sevilla, en el que desde 1498 se hallaba incluido el del reino de Murcia, y todos los restantes costeros, denunciaron que ciertos vecinos de Murcia y su comarca vendían sus lanas a genoveses; quienes, tras empaquetarlas, las llevaban al puerto de Cartagena para su exportación sin abonar el impuesto, pues eran remitidas por los residentes exentos que, a pesar de haberlas vendido, fraudulentamente alegaban que eran suyas. Otra mistificación consistía, como se ha dicho, en que los forasteros se avecindasen falsamente, tanto los castellanos como los extranjeros; como hicieron algunos poderosos habitantes en Murcia. Mientras que los vecinos de Lorca compraban género fuera de la localidad y luego lo vendían exento como si fuese de su cosecha. Hasta los de los Vélez, también francos, daban poderes a forasteros para que alegasen que las mercancías que transportaban eran suyas, de manera que transitasen sin abonar el derecho. Por todo ello, la soberana ordenó al corregidor de la capital que obligase a pagar almojarifazgo y diezmo a los foráneos avecindados que no viviesen habitualmente en esos lugares con sus familias, así como de las mercancías vendidas fraudulentamente por los vecinos o de las por ellos compradas ${ }^{14}$.

\footnotetext{
13 AMM, AC 1427-28, fols. 16v-17r, 30v-33v, 48r, 66v, 74r, 82r-v; 1437-38, fol. 50v; González Arce (1998: 241).

14 CODOM, XVIII: 234-242; XXIII: 373-374, 471-476, 502-506, 614-624, 702-703. En 1487 los Reyes Católicos ratificaron a los moros murcianos de la Arrixaca sus privilegios concedidos por Fernando IV en 1305, que los redimió del pago de toda clase de tributos, salvo almojarifazgo (CODOM, XIX: 581-589). En 1493, dos antiguos vecinos de Murcia, de origen judío, que habían abandonado Castilla tras la orden de expulsión del año anterior, reclamaron estar exentos tras su conversión y retorno (AMM, leg. 4.281, 59)
} 
5. Los privilegios de los privilegiados

Los privilegios de exención llegaron incluso a territorios de fuera de la Corona de Castilla. En 1482 los Reyes Católicos se los otorgaron a Elche y Crevillente, si bien ya los tuvieron en el siglo XIII, cuando pertenecían al reino de Murcia, antes de ser conquistadas por Jaime II e incorporadas al de Valencia. Por dos motivos, porque ahora ambas Coronas, la castellana y la aragonesa, volvían a estar unidas y porque dichas villas pertenecían a Gutierre de Cárdenas, comendador de León y contador mayor de la hacienda castellana, a quien habían sido entregadas en pago a sus servicios bélicos. Ahora los monarcas les dieron las exenciones ex novo, como si se tratara de la primera concesión, sin duda para evitar confusiones y para mayor beneficio de sus habitantes $y$, por ende, de su señor. Caso de la liberación del diezmo, aduanas, almojarifazgo, pasajes, portazgo, rodas, castillerías y otros tributos de las mercancías llevadas de los lugares susodichos a Castilla, y de las que hiciesen el camino inverso. En 1499 el fisco real demandó a dicho comendador ante el baile general de Orihuela, por la compra de la villa de Aspe sin haber pagado el correspondiente almojarifazgo; el aristócrata apeló ante Fernando el Católico, que anuló el proceso y mandó que no se le cobrase la exacción ${ }^{15}$.

En 1498 los soberanos remitieron a los recaudadores de rentas del reino de Murcia y obispado de Cartagena una carta comunicándoles que los arrendatarios de las minas de alumbre de dicho reino, principalmente situadas en Mazarrón, pertenecientes a Diego López Pacheco, duque de Escalona y marqués de Villena, y al adelantado Juan Chacón, les habían pedido que se respetase la franqueza que el mineral extraído de dichas explotaciones tenía para no abonar diezmo aduanero, almojarifazgo u otros derechos de paso, puesto que últimamente no les era guardada. Sin embargo, dicha merced era utilizada para traficar con otras mercancías sin abonar impuestos. Tal y como denunciaron los almojarifes en 1503, que acusaron al arrendatario de las minas de la parte del marqués de Villena de no pagar almojarifazgo por los alimentos y otros suministros que llevaba desde Murcia a las mismas. En 1504 los Reyes Católicos dispusieron, ante la escasez de subsistencias, que Murcia dejase pasar el cereal que era allí acarreado por tierra para sostenimiento de los mineros. En 1510 eran los vecinos de Lorca y Murcia los que, aprovechando la exención de los alumbres murcianos, introducían esta materia prima procedente de otras partes y la vendían sin pagar almojarifazgo ${ }^{16}$.

Otros personajes eximidos de derechos aduaneros fueron los emisarios reales, como el zaragozano Lope de Arriaga, que servía de mensajero entre el rey Fernando y el virrey de Sicilia,

\footnotetext{
15 AMM, CR 1478-1488, fols. 79r-81v. Archivo Histórico Nacional, Sección Nobleza (AHN-N, Baena, caja 165, 18-19; caja 190, 29.

16 AHN-N, Frías, caja 771, 34-35. Archivo Histórico Provincial de Murcia, protocolo 363, fol. 347. AMM, AC 1504-05, fol. 8v. CODOM, XX: 1.004-1.005; XXIII: 618
}

al que el monarca redimió en 1499 de toda clase de aranceles por sus pertenencias en sus frecuentes viajes entre Castilla, Aragón y Sicilia ${ }^{17}$.

Mientras que en 1502 era el propio arrendatario del almojarifazgo de Murcia, por entonces incluido en el de Sevilla, Alonso de Herrera, el que en su nombre y en el de los otros arrendatarios ordenaba a su recaudador en Murcia, García Gutiérrez de Madrid, que no lo demandase de los vecinos de Aledo, que estaban exentos de abonarlo en sus aprovisionamientos. Más que el reconocimiento de la franqueza, esta actuación parece que atendió a las influencias del comendador de la localidad santiaguista ${ }^{18}$

\section{Conclusión}

A lo largo de las páginas precedentes, se ha realizado un recorrido por los privilegios de exención que afectaron a las distintas localidades del antiguo reino medieval de Murcia (actuales provincias de Murcia y Albacete), entre la conquista castellana del siglo XIII y la primera mitad del XVI, en lo relativo a la fiscalidad aduanera y comercial. En qué consistieron; a quienes afectaron; cómo se aplicaron, evolucionaron, se transformaron, se redujeron y desaparecieron en algunos casos; quien los otorgó, amplió o redujo, y con qué objetivos; las consecuencias de estas acciones; $y$, sobre qué rentas mercantiles recayeron.

Se trata de un asunto complejo, que comienza por valorar la naturaleza y el alcance de las exacciones fiscales aquí tratadas, para las que no se conocen todos los supuestos extractivos que comprendieron, durante todo el lapso de tiempo abarcado por este estudio, debió a su carácter cambiante y variopinto. Sobre todo, en el caso del almojarifazgo, que fue, en realidad, un conjunto de rentas dispares y muy volubles al que he dedicado numerosos trabajos, con los que he podido desenmarañar más de una treintena de derechos comprendidos en su seno, que no siempre fueron exactamente los mismos en las distintas localidades en las que se exigieron, ni a lo largo de los siglos. Menor complejidad revistieron otros arbitrios sobre el tráfico de mercancías, como el portazgo o el diezmo aduanero; aunque el primero de estos también registró variaciones, localismos y pudo albergar en su seno distintos supuestos contributivos, como también he puesto de manifiesto en algunas de mis publicaciones anteriores.

\footnotetext{
17 CODOM, XX, p. 561.

18 Archivo Municipal de Totana, Varios, 1502-VII-17. Por su parte, el comendador de Cieza, cautivo en Granada, obtuvo en 1477 exención en todos los bienes y mercancías allí llevados a cambio de su rescate (AGS, RGS, 1477-11, 310).
} 
Dejando aparte estas consideraciones, el presente artículo pone de manifiesto las intenciones de los monarcas castellanos de los primeros siglos tras la conquista del reino de Murcia, que consistieron en repoblar el territorio a casi cualquier precio, para asegurar su ocupación. De modo que, y debido a lo poco atractiva que resultaba una región semiárida y peligrosa, por encontrarse en la frontera marítimo terrestre con el Islam, se debieron conceder excepcionales y generosas mercedes a los potenciales repobladores cristianos procedentes del norte peninsular, por otro lado poco numerosos debido al esfuerzo realizado en otras zonas más atractivas, como Andalucía, que habían acogido a la mayor parte de los efectivos demográficos disponibles. Por tales motivos, los nuevos murcianos gozaron durante muchos años de privilegios de exención en materia económica, sobre todo en el ámbito comercial, con el objetivo de retenerlos en el territorio, donde pagaban menos gravámenes que en otros reinos castellanos; tanto por lo que producían y luego exportaban, como por lo importado para su consumo. Ventajas que recayeron de forma preferente sobre los propios habitantes del lugar, antes que sobre mercaderes foráneos, de manera que resultaron ser la base para la aparición o atracción de gentes especializadas en el ámbito comercial y de los negocios.

En la mayoría de los casos, estas redenciones fiscales en materia comercial fueron trasvasadas desde la antedicha Andalucía, en especial desde Sevilla y Córdoba, a partir de cuyos derechos locales se repoblaron la mayor parte de las plazas murcianas. Se trató de privilegios de exención primero aplicados en dichas ciudades andaluzas, y luego trasvasados a las murcianas. De manera que, como en casi todos los casos, tales concesiones terminaron por cambiar a lo largo del tiempo, pues en su mayoría fueron mermadas una vez que mejoró la situación económica, aumentó la densidad de población, se redujo el peligro fronterizo, etc., las ciudades andaluzas y murcianas mantuvieron contactos y consultas sobre el carácter de las prebendas originales, y a quiénes afectaban y cómo se aplicaban; gracias a lo cual he podido analizar su evolución en el tiempo.

Algo que ha sido posible, además, por contar con las sucesivas confirmaciones y modificaciones que los diferentes monarcas hicieron de tales corpus de privilegios. A instancias de las propias localidades afectadas, que intentaron que cada rey rubricase la ratificación de las gracias originales; o bien se opusieron o resistieron a que redujesen las mismas. Junto a esta actividad institucional en favor de preservar sus márgenes de privilegio por parte de los distintos concejos, lo que no sólo beneficiaba a sus vecinos, por reducir sus cargas fiscales, sino que también atraía a ellos una mayor actividad económica y mercantil, al contar con mayores ventajas arancelarias que otros, incluso cercanos, igualmente se registraron enfrentamientos entre tales poblaciones vecinas o próximas. Pues en la guerra por asentar mayor volumen de negocio a sus municipios, no dudaron en no reconocer, no observar o hacerlo en grado mínimo las mercedes de los concejos competidores y sus habitantes. Estas prácticas movieron a los consistorios a denunciar tales abusos ante la corona, o incluso a amenazar con represalias comerciales a los otros con los que mantenían enfrentamientos. Situación que nos recuerda las actuales re- bajas y desgravaciones fiscales competitivas entre comunidades autónomas, o entre países dentro de la Unión Europea y a nivel mundial, en las que el recurso a la competencia desleal está a la orden del día.

También los afectados por tales guerras comerciales, los propios comerciantes, recueros o agentes mercantiles tomaron la iniciativa para defender sus intereses; demandado para ello a los concejos infractores, ante la justicia local o real, o reclamando el respaldo de sus respectivos municipios. Lo que nos ha dejado un gran número de testimonios de gentes corrientes que emprendieron acciones legales en su beneficio, algo poco frecuente, debido a la escasa documentación que nos ha llegado del período medieval para la corona de Castilla. En la cual el reino de Murcia es la gran excepción, al contar con más nutridos fondos que en otras partes, con los que se puede descender, como en este caso, al análisis de detalle de las situaciones por las que pasaron las personas que lo habitaron, en su intento de preservar las ventajas con las que contaron. De manera que es muy amplia la casuística a este respecto analizada en este trabajo. Tal vez uno de los aspectos más interesantes del mismo. 


\section{Bibliografía}

ABBOUD-HAGGAR, S. (1997): "Leyes musulmanas y fiscalidad mudéjar", Finanzas y fiscalidad Municipal, V Congreso de Estudios Medievales, Ávila, Fundación Sánchez-Albornoz.

ABBOUD-HAGGAR, S. (2008): "Precedentes andalusíes en la fiscalidad de las comunidades mudéjares", En la España Medieval, 31, pp. 475-512.

CODOM, Colección de Documentos para la Historia del Reino de Murcia, Real Academia Alfonso X el Sabio, Murcia.

COLLANTES DE TERÁN, A. (2013): "Los sevillanos ante el impuesto: la exención fiscal (siglos XIII-XVI)", Minervae Baeticae. Boletín de la Real Academia Sevillana de Buenas Letras, 2a época, 41, pp. 293-318.

EPSTEIN, S.R. (2009): Libertad y crecimiento. El desarrollo de los estados y de los mercados en Europa, 1300-1750, Valencia, Universidad de Valencia.

GARCÍA DÍAZ, I. (2007): Documentación medieval del Archivo Municipal de Lorca (1257-1504), Murcia, Universidad de Murcia.

GONZÁLEZ ARCE, J.D. (1992a): "La política fiscal de Alfonso X en el reino de Murcia: portazgo y diezmos", Studia Historica, Historia Medieval, 10, pp. 73-100.

GONZÁLEZ ARCE, J.D., (1992b): “Ordenanzas y fuero concedidos a la ciudad de Córdoba por Fernando III", Cuadernos de Estudios Medievales, 17, pp. 399-411.

GONZÁLEZ ARCE, J.D., (1995): "El artesanado en los fueros del reino de Murcia", Anuario de Estudios Medievales, 25/1, pp. 81-125.

GONZÁLEZ ARCE, J.D. (1998): Los gremios medievales de Murcia. Organización y estructura del artesanado urbano en el modo de producción feudal, CD-rom, Murcia, Universidad de Murcia.

GONZÁLEZ ARCE, J.D. (1999): “Producción artesanal y fiscalidad comercial, Murcia ss. XIV-XV", Murgetana, 99, pp. 93-107.

GONZÁLEZ ARCE, J.D. (2002a): "Fiscalidad comercial y privilegios de exención en Chinchilla (S. XIII-XVII)", en Segundo Congreso de Historia de Albacete, II Edad Media, Albacete, Instituto de Estudios Albacetenses, pp. 77-90.

GONZÁLEZ ARCE, J.D. (2002b): La fiscalidad del señorío de Villena en la baja Edad Media, Albacete, Instituto de Estudios Albacetenses.

GONZÁLEZ ARCE, J.D. (2004): “Almojarifazgo y privilegios de medievales de exención en un pleito de Chinchilla del siglo XVII", en Homenaje a Miguel Rodríguez Llopis, Albacete, pp. 141-164.

GONZÁLEZ ARCE, J.D. (2005): "Las rentas del almojarifazgo de Toledo", Anales Toledanos, 61, pp. 39-70.

GONZÁLEZ ARCE, J.D. (2012): "De conjunto de rentas a impuesto aduanero. La transformación del almojarifazgo durante el siglo XIV en el reino de Murcia", Anuario de Estudios Medievales, 42/2, pp. 669-696.

GONZÁLEZ ARCE, J.D. (2013): “Los arrendatarios del almojarifazgo de Toledo en el siglo XV", Miscelánea Medieval Murciana, 37, pp. 99-119.

GONZÁLEZ ARCE, J.D. (2014a): "Agentes fiscales en el almojarifazgo del reino de Murcia (siglo XV)", en Agentes de los sistemas fiscales en Andalucía y los reinos hispánicos (siglos XIII-XVII): Un modelo comparativo, Madrid, Instituto de Estudios Fiscales, pp. 85-115.

GONZÁLEZ ARCE, J.D. (2014b): "De la fiscalidad musulmana a la descomposición del almojarifazgo. La formación de las haciendas municipal, eclesiástica y señorial en Toledo (siglos XI-XVI)", Medievalismo, 24, pp. 123170.

GONZÁLEZ ARCE, J.D. (2014c): “La composición de los almojarifazgos señoriales del reino de Sevilla, siglos XIII-XV", Historia. Instituciones. Documentos, 41, pp. 243-273.

LADERO QUESADA, M.A. (1969): "Almojarifazgo sevillano y comercio exterior de Andalucía en el siglo XV", Anuario de Historia Económica y Social, 2, pp. 69-115.

LADERO QUESADA, M.A. (1993): Fiscalidad y poder real en Castilla (12521369), Madrid, Universidad Complutense.

LÓPEZ SERRANO, A. (1997): Yecla: Una villa del señorío de Villena. Siglos XIII al $X V I$, Murcia, Academia Alfonso X el Sabio.
ORTUÑO MOLINA, J. (1997): “La aduana del puerto de Yecla como fuente de rentas", Yakka, 8, pp. 187-194.

PORRAS ARBOLEDAS, P.A. (1992): “Los portazgos en León y Castilla durante la Edad Media. Política real y circuitos comerciales", En la España Medieval, 15, pp. 161-211. 